\title{
'I'm Not There Anymore': Film Performance Affects and the Loosening of Narrative
}

PAVEL PROKOPIC (1)

(3)

Open Library of Humanities

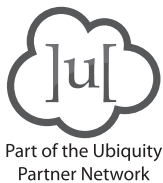

CORRESPONDING AUTHOR:

\section{Pavel Prokopic}

University of Salford, GB

pavel.prokopic@gmail.com

KEYWORDS:

Affect; Performance; Close-up; Deleuze; Directing; Narrative

TO CITE THIS ARTICLE:

Prokopic, P. 2021. 'I'm Not There Anymore': Film Performance Affects and the Loosening of Narrative. Open Screens, 4(1): 7, pp. 1-4. DOI: https://doi.org/10.16995/os.38 


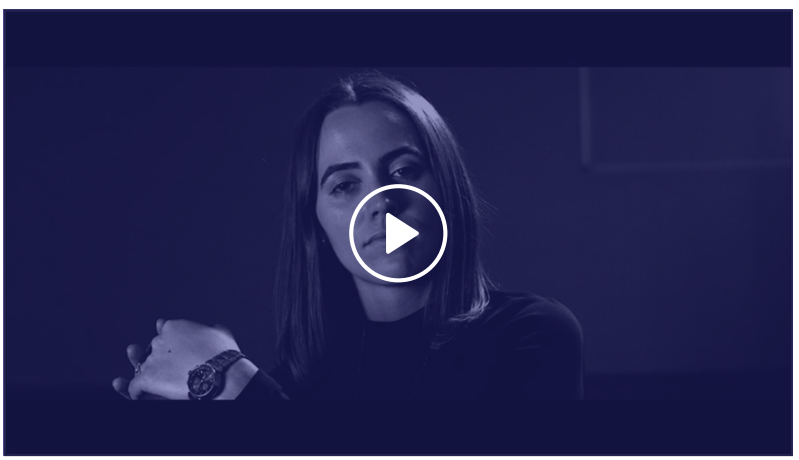

\section{RESEARCH STATEMENT}

The film emerged from a wider, AHRC-funded practiceas-research $\mathrm{PhD}$ entitled Affective Cinema, which experiments with cinematographic and directorial techniques, and methods of working with performers. The research generates film structures that disrupt or offset narrative, semiotic and/or spatial coherence by the production of audio-visual affects. In this way, a certain boundary is being explored between the representational and the non-representational, which gives rise to a sense of 'affective significance' - a meaning that is felt before it can be thought. The research applies concepts in film ontology and the theoretical field surrounding Deleuzian affect in order to rethink methods of film production and directing actors, as well as develop new methods informed directly by the theoretical/philosophical basis of the project. The insights into the theory are expanded through the practice, as well as directly embedded in it, since the film practice element demonstrates the synthesis of the theory that is at the heart of the project.

Affects are defined by Gilles Deleuze and Félix Guattari (1994) as the 'nonhuman becomings of man' (169, emphasis in the original): they exist independently of the human being as a subject - they exist as 'sensible experiences in their singularity, liberated from organising systems of representation' (Colebrook 2001: 22). The Deleuzian concept of 'nonhuman' is fundamentally related to these impersonal, undifferentiated intensities of affects, as opposed to the human world of language, meaning, and subjectivity. Affect can also be placed in a useful opposition to emotion, which is a conceptualised, habitual form of affect. Steven Shaviro (2010) and Brian Massumi (2002), in their writings inspired by Deleuze, distinguish between affect and emotion in this way. Emotion, for them, is a specific and qualified experience of a subject, confining or reducing affect to an intelligible (human) form, which nevertheless always has a certain affective surplus beyond meaning and outside the boundaries of subjectivity (Shaviro 2010: 4).

In I'm Not There Anymore, the sense of affects is generated and explored chiefly through the aspect of film performance. Elena Del Río (2008) identifies film as a 'privileged medium for the exhibition of bodies' (10). In film, as Del Río specifies, 'whatever happens to a body becomes instantly available to perception. Thus, the performing body presents itself as a shock wave of affect, the expression-event that makes affect a visible and palpable materiality' (10). She considers performance to be the element in film that has the potential to defy and disrupt film's narrative and formal structuring principles: 'as an event, performance is cut off from any preconceived, anterior scenario or reality. In its fundamental ontological sense, performance gives rise to the real' (4). She sees affect as an intrusion of the new into the repetitive and familiar structures in film, and the moving (performing) body - which is quite distinct from the (human) subjectivity of the performer - as being the very source of this disruption, and in this manner offsetting the 'totalizing imposition of generic meaning' (15).

This effect is emphasised in film by the use of closeup shots of performers, which have the potential to reveal nuanced movements of the body, in particular the face; or as Mary Ann Doane (2003) observes about the close-up, 'any viewer is invited to examine its gigantic detail, its contingencies, its idiosyncrasies. The closeup is always, at some level, an autonomous entity, a fragment, a "for-itself"' (90). The close-up exposes the nonhuman nature of the body as the real, beyond coherent gestures and representation of the character and narrative; it is the most efficient revelatory function of film, which, according to Dieter Mersch (2012), gives us 'enhanced visibility, concurrent with a never-before-seen manifestation of the human body' (448). Furthermore, for Deleuze, the face in a close-up shot 'gathers and expresses the affect as a complex entity, and secures the virtual conjunctions between singular points of this entity' (1986: 103), making every instant of film performance markedly unique, singular. The combination of close-up shots and a style of performance that prioritises affects over narrative/dramatic representation and coherence has resonances with various works of experimental and art cinema; in particular Bresson's Diary of a Country Priest (1951), Bergman's Persona (1966), Reggio's Visitors (2013), Dwoskin's Central Bazaar (1976) and Figgis' Co/ Ma (2004). All of these films use close-up shots very effectively - giving rise to singular affects through the complex expressive power of the face. Applying the same technique, I'm Not There Anymore generates affects in various moments, which, because of their singularity, make these shots relatable to - yet also radically distinct from - the stated film examples.

The methods applied to working with performers in I'm Not There Anymore focused on maximising the possibility of generating nonhuman affects by disrupting conventional directorial approaches, in order to achieve random rather than meaningful, representational results in relation to the narrative. This approach, in turn, created 
new, unpredictable connections between the narrative represented in the spoken words and the affects in the performance, offsetting coherent meaning and instead generating the potential for a feeling of meaning: affective significance. This effect was later emphasised through the editing process, which focused on selecting takes of performance based on their singular affective value, rather than supporting the dramatic/emotional coherence and unification of the narrative.

One of the most significant methods of directing performers tested and applied when making the film was the use of 'action verbs'. Defining the performance objective in a given moment by the use of an action verb (a verb that represents a specific action towards the other performer) is a method stemming from the acting system developed by Konstantin Stanislavski for stage acting, which has since been widely applied in film acting and directing (see, for example, Weston 1996). When working with action verbs in order to maximise the affective impression of performance, rather than its representational function in respect of the narrative, I realised that as long as the performer naturally understands the basic meaning of the word (as a user of the given language), then there is no reason to connect to the word rationally. Rather, the sound of the word already conveys the action: it inspires it. The word is the action in a way: it responds to the action mimetically rather than as a randomly assigned signifier. However, instead of being onomatopoetic (mimetic in relation to a specific referent in the world), the action verb reflects a 'non-sensuous similarity', as Walter Benjamin describes it:

Language is the highest application of the mimetic faculty: a medium into which the earlier perceptive capabilities for recognising the similar had entered without residue, so that it is now language which represents the medium in which objects meet and enter into relationships with each other, no longer directly, as once in the mind of the augur or priest, but in their essences, in their most volatile and delicate substances, even in their aromata (1979: 68).

Rather than relationships between objects that Benjamin refers to, it is a physical action that is at stake in the case of the action verb. Instead of denoting a relation to a referent (action) in sensuous reality, the action verb expresses the pre-rational bodily sense of the action, bypassing in the process the separation between the signifier and the referent, and inspiring instead a direct impulse to act.

The action-verb technique can give rise to random results in respect to a meaningful dramatic structure when a verb is given to the actor that doesn't bear a logical connection to the intention or attitude that would seem appropriate in the moment. Or, when an action verb is given to the performer for the entire take of the dialogue, one can observe an 'oscillation' of the verb in relation to the scene: in certain moments the verb corresponds logically with a line of dialogue, in other moments it goes against the logic of the line in a significant (affective) way; and in some moments it seems to give rise to a 'false' intention - an instance of performance that appears forced, self-conscious. For example, the delivery of 'she was looking at me like I had something' (01:02 into the film) is the result of the action verb 'worry', which dramatically emphasises the meaning of the words in a singular way. Whereas the line 'blanket covering her legs' (00:34) results from the use of the verb 'enchant', which creates an affective dissonance with the meaning of the words.

Ultimately, any outcome of the action verb direction can be potentially valuable to structuring a film based on affective significance. This is because the approach aiming to maximise the affective value of performance, rather than its dramatic coherence, doesn't anticipate any specific results in the moment of production. This resonates with Robert Bresson's (1977) approach to directing and working with performers; for Bresson 'the real is not dramatic ... drama will be born of a certain march of non-dramatic elements' (46), in the 'agony of making sure not to let slip any part of what I merely glimpse, of what I perhaps do not yet see and shall only later be able to see' (45). In the moment of production, Bresson advises (to himself) to 'be as ignorant of what you are going to catch as is a fisherman of what is at the end of his fishing rod. (The fish that arises from nowhere)' (59, emphases in the original).

While the research uniquely synthesises aspects of film theory and philosophy in order to directly apply and test this in practice, it also generates insights into filmmaking practices and directorial methods that bear relevance to wider film production and education. As I explain throughout this research statement, and evidence through the film, the philosophy of Deleuze and Benjamin, as well as many others, was a potent and productive basis for this creative practice. It has led to new practitioner insights, such as the innovatory use of action verbs, or post-production methods focused on maximising the affective connections within the audio-visual sequence rather than supporting narrative coherence. Furthermore, the film work itself represents a form of new knowledge, especially as a direct outcome of the practice-as-research process. Or as Henk Borgdorff (2011) succinctly puts it, "the experiences and insights that artistic research delivers are embodied in the resulting art practices and products. In part, these material outcomes are non-conceptual and non-discursive, and their persuasive quality lies in the performative power through which they broaden our aesthetic experience, invite us to fundamentally unfinished thinking, and prompt us 
towards a critical perspective on what there is' (47). The value and strength of this research project ultimately lie in this 'performative power' opening up 'fundamentally unfinished thinking', which only the film alone can communicate, by entangling the attentive viewer in a momentary affective resonance.

\section{COMPETING INTERESTS}

The author has no competing interests to declare.

\section{AUTHOR AFFILIATION}

Pavel Prokopic (D) orcid.org/0000-0003-1428-6794

University of Salford, GB

\section{REFERENCES}

Benjamin, W. 1979. Doctrine of the Similar. New German Critique, Spring No. 17: 65-69. DOI: https://doi. org/10.2307/488010

Borgdorff, H. 2011. The Production of Knowledge in Artistic Research. In Biggs, M and Karlsson, $\mathrm{H}$ (eds.), The Routledge Companion to Research in the Arts. London, New York: Routledge.

Bresson, R. 1977. Notes on Cinematography. New York: Urizen Books.

Colebrook, C. 2001. Gilles Deleuze. London, New York: Routledge. DOI: https://doi.org/10.4324/9780203241783

Del Río, E. 2008 Deleuze and the Cinemas of Performance: Powers of Affection. Edinburgh University Press. DOI: https:// doi.org/10.3366/edinburgh/9780748635252.001.0001

Deleuze, G. 1986. Cinema 1: The Movement Image. London: The Athlone Press. DOI: https://doi.org/10.5040/9781350251977

Deleuze, G and Guattari, F. 1994. What is Philosophy? New York: Columbia University Press.

Doane, MA. 2003. The Close-Up: Scale and Detail in the Cinema. Differences: A Journal of Feminist Cultural Studies, 14(3): 89-111. DOI: https://doi.org/10.1215/10407391-143-89

Massumi, B. 2002. Parables for the Virtual: Movement, Affect, Sensation. Durham \& London: Duke University Press. DOI: https://doi.org/10.1215/9780822383574

Mersch, D. 2012. Passion and Exposure: New Paradoxes of the Actor. In Sternagel, J et al (eds.) Acting and Performance in Moving Image Culture: Bodies, Screens, Renderings. Transcript Verlag, 447-77. DOI: https://doi.org/10.14361/ transcript.9783839416488.447

Shaviro, S. 2010 Post-Cinematic Affect: On Grace Jones, Boarding Gate and Southland Tales. Film-Philosophy, 14(1): 1-102. DOI: https://doi.org/10.3366/film.2010.0001

Weston, J. 1996. Directing Actors: Creating Memorable Performances for Film and Television. Michael Wiese Productions.

\section{FILMOGRAPHY}

Central Bazaar. 1976. [Film] Stephen Dwoskin. UK: British Film Institute.

Co/Ma. 2004. [Film] Mike Figgis. Slovenia: Coma-Film.

Diary of a Country Priest (Journal d'un curé de campagne). 1951. [Film] Robert Bresson. France: Union Générale Cinématographique.

Persona. 1966. [Film] Ingmar Bergman. Sweden: Aurora. Visitors. 2013. [Film] Godfrey Reggio. USA: Cinedigm.

TO CITE THIS ARTICLE:

Prokopic, P. 2021. 'I'm Not There Anymore': Film Performance Affects and the Loosening of Narrative. Open Screens, 4(1): 7, pp. 1-4. DOI: https://doi.org/10.16995/os.38

Submitted: 15 July $2020 \quad$ Accepted: 07 October $2020 \quad$ Published: 07 June 2021

COPYRIGHT:

(c) 2021 The Author(s). This is an open-access article distributed under the terms of the Creative Commons Attribution 4.0 International License (CC-BY 4.0), which permits unrestricted use, distribution, and reproduction in any medium, provided the original author and source are credited. See http://creativecommons.org/licenses/by/4.0/.

Open Screens is a peer-reviewed open access journal published by Open Library of Humanities. 